\title{
Customer Loyalty in Retail Banking
}

\author{
$\mathrm{PhD}$ candidate Krista Neykova \\ D. A. Tsenov Academy of Economics - Svishtov, Bulgaria \\ k.neykova@uni-svishtov.bg
}

\begin{abstract}
The concept of brand loyalty has intrigued researchers and practitioners for over 95 years. The extensive attention that is paid to the "loyalty" phenomenon, is due to the fact that, it is an integral part of companies' mission to create value - for customers and investors. With increasing the intensity of competition and globalization of financial markets, building customer loyalty becomes a strategy of critical significance for the success of financial companies. A problematic area in the theory of loyalty in the service sector is the variety in definitions and lack of consistency about concepts, views and opinions with respect to what is loyalty to a financial service provider, what are its dimensions and how to be defined, measured and managed. Which this in mind, the main focus of this paper is studying the theoretical fundamentals of customer loyalty in retail banking and outputting a relevant conceptual definition for the phenomenon. Basic operational and conceptual definitions are discussed and the specific features of customer loyalty are clarified from a financial sector perspective.
\end{abstract}

Keywords: loyal, customer loyalty, retail banking, service sector

JEL Code: M31; doi:10.36997/IJUSV-ESS/2019.8.2.140

\section{Въведение}

Глобалните тенденции на пазара на банковия продукти ${ }^{1}$ водят до необходимост от префокусиране на усилията на банките и промяна в модела на управление на финансовите институции. Финансовите компании трябва да заприличат все повече на тьрговци на дребно във ,войната за потребителските долари“ (Jain, Pinson, \& Malhotra, 1987, p.3). Обширното внимание което се обръща на лоялността в академичните среди и бизнес общността е в резултат на потенциалните икономически ползи и ефекти за бизнес организациите от инвестиции в развитие и задържане на клиентите. От една страна, икономическите ползи от лоялността с които фирмата може да бъде облагодетелствана намират проявление в склонността на лоялните клиенти да проявяват ценова нечувствителност, свързани покупки, задълбочаване на взаимоотношенията с доставчика на услуги и т.н. От друга страна, отражението на текущите нива на клиентска лоялност върху пазарното представянето на компаниите може да бъде аргументирано с ефекта и въздействието на явлението върху показателите за оценка на просперитета и конкурентните позиции на бизнес организациите (например приходите, разходите, печалбите, пазареният дял и т.н.). В съвременни пазарни условия дългосрочния успех на банките изисква генерално преобръщане на мирогледа и преоценка на стратегиите във връзка с мениджмънта на лоялността и начина по който се интерпретира и измерва явлението.

Обикновено маркетинговите стимули и инициативи, инициирани от организациите в сектора на потребителски стоки и стоките за дълготрайна употреба, насочени към насьрчаване на задържане на потребителската лоялност към бранда, вероятно не биха оказвали същото въздействие върху потребителите във финансовия сектор. Извежданите предположения за лоялността към бранда за продукти с високо съдържане на материалновеществени доказателства не биха били релевантни за лоялността в сектора на услугите. В подкрепа на това се откриват аргументи в изследвания доказващи, че видът, степента и силата на проявление на лоялността е специфична от гледна точка на продуктовата

\footnotetext{
${ }^{1}$ Промени в пазарната конюнктура, технологичен напредък, дигитализация, регулаторни политики, промяна в демографската структура на населението, засилена клиентска мобилност, спада в доверието на клиентите и пр. (Младенова, 2015).
} 
категория, т.е. определени продуктови категории в повече или по-малак степен предразполагат проява на специфично лоялно клиентско поведение (Farley, 1964). Нуждата от диференцирано изучаване на специфичните аспекти на проявление на лоялността в сектора на услугите, в т.ч. и банковия, става отправен момент в редица теоретични и емпирични публикации(Caruana, 2002; Hallowell, 1996; Jain et al., 1987; Rundle-Thiele \& Bennet, 2001; Rust, Zaborik, \& Zahorik, 1993; Wugayan \& Pleshko, 2010). Отчитайки това, целта на настоящата разработка е изясняване на сыщността на понятието лоялност при банкиране на дребно и извеждане на характерните черти на явлението вследствие на особеностите на банковия сектор.

\section{1. Теоретичен фундамент на клиентската лоялност на пазара на банкови продукти}

От теоретична гледна точка при изучаване на лоялността към марката се разкриват три основни подхода, които биват възприемани в академичните среди при концептуализиране и операционализиране на лоялността като маркетингов феномен. В изследванията за лоялността към бранда, значителен интерес придобива извеждането на оценки за лоялността в две основни категории - поведенчески, отношенчески и комбинирани. При поведенческата лоялност към бранда, направленията при изследване на явлението гравитират около извеждане на показатели, като последователност при покупка, дял от бюджета, дял от покупката, честота на покупките и прочие измерители свързани с действително поведение. От гледна точка на отношенческата лоялност към бранда, изследванията акцентират върху извеждане на теоретично обосновани показатели за оценка на лоялността, засягащи различни аспекти от психологическото състояние на потребителя (нагласи, заявени предпочитания, заявени намерения за покупка и препоръка на марката и т.н.) (Dick \& Basu, 1994). Отнишенческият подход е особено популярен в маркетинговите среди, тъй като отношенческите мерки могат да бъдат използвани като база за аргументиране на причините или факторите водещи до проява на лоялност към марката (Guest, 1944; Olson \& Jacoby, 1971).

Потенциала за генериране на лоялност в сектора на услугите значително надвишава възможностите за изграждане на клиентска лоялност в останалите типове пазари. Освен лоялност основана на действително поведение, сектора на услуги благоприятства изграждане на нагласи, инкорпорирайки ангажираността и намеренията за покупка в отношението към доставчика на услуги. В допълнение, ниската вероятност за смяна на доставчика предопределя високия дял на изключително лоялните купувачи в категорията. В сектора на услугите обичайно преобладава моногамен тип лоялност, но вероятността за лоялност към два или повече предложителя на услуги нараства в зависимост от силата и посоката на влияние на факторите на лоялността върху потребителския избор. Така например Шарин Рандъл-Тиле и Ребека Бенет (Rundle-Thiele \& Bennet, 2001) правят опит за обобщаване на концептуалните подходи при изследване на лоялността, с оглед различията на трите основни типове пазари - бързооборотни потребителски стоки, стоки за дълготрайна употреба и пазара на услуги. Според авторите тези различия произлизат от специфичните пазарни характеристики и отражението им върху променливи като вероятност за смяна на марката, честотата на покупките, дял от категорията, ангажираност, намерение за покупка и повторна покупка, нивата на възприемания риск и пр. В Таблица 1 са представени основните различия между трите типа пазари, с оглед на типологията на лоялността и степента на действие на потенциалните причинители на лоялността.

Ранните изследвания, посветени на лоялността при банкиране на дребно, представят, че лоялността в сектора на финансовите услуги е единствено проявление на продължително потребление във времето (Fry, Shaw, Haehling von Lanzenauer, \& Cecil, 1973; Meidan, 1996). 
Така например, според Фрай и колектив ,лоялността може да бъде измерена чрез проследяване на клиентските сметки през определен период от време и отбелязване на степента на непрекъснатост в потреблението“(Fry et al., 1973, p.518). Авторите провеждайки проучване което има за цел да установи наличието или липсата на непрекъснатост в потреблението на банкови продукти от една и съща финансова компания. Те установяват, че на годишна база само около $3 \%$ от клиентите сменят банката си, въпреки че лоялността на клиентите е намалявала в други сектори на икономиката. Последното е в потвърждение на идеята, че клиентската лоялност в сектора на банковите услуги е по-силно изразена, както и, че силата и посоката на проявление на лоялността е силно зависима от продуктовата категория. Фрай и колектив възприемат поведенческия подход при дефиниране на явлението. От тяхната дефиниция се изяснява, че клиентската лоялност към финансовата организация е единствено функция на поведенческа реакция към обекта на оценка, отричайки необходимостта от отчитане на свързаните с нагласите аспекти на лоялността. Възприемайки дефиницията на Фрай, Мейдън разглежда лоялността като „непрекъснато потребление от конкретна банка от страна на клиент, наблюдавано с течение на времето “(Meidan, 1996, p.31). Той твърди, че всеки клиент изразява определена степен на лоялност към финансовата компания, тъй като тя оперира с парите му.

Таблица 1. Обобщение на характеристиките и мерките за лоялност към марката

\begin{tabular}{|c|c|c|c|}
\hline & $\begin{array}{c}\text { Бързооборотни потребителски } \\
\text { стоки }\end{array}$ & Стоки за дълготрайна употреба & Услуги \\
\hline \multicolumn{4}{|l|}{ Поведенческа лоялност } \\
\hline Смяна на марката & да & няма & няма \\
\hline Честота на покупка & високи & ниска & от средна до висока \\
\hline Тип лоялност & полигамна & моногамна & моногамна или полигамна \\
\hline Дял от категорията (\%) & варира от 1 до 60 & 100 & обикновено 80 или повече \\
\hline Дял на моногамни купувачи & $\begin{array}{c}\text { между } 10 \text { и } 30 \text { в зависимост от } \\
\text { броя на марките }\end{array}$ & & приблизително 80 \\
\hline \multicolumn{4}{|l|}{ Отношенческа лоялност } \\
\hline Ангажираност & променлива & неизвестно & висока \\
\hline Намерение за покупка & променливо & неизвестно & високо \\
\hline \multicolumn{4}{|l|}{ Драйвери на лоялността } \\
\hline Възприеман риск & няма & да & Да \\
\hline Инерция & няма & не & Да \\
\hline Навик & да & не & Да \\
\hline Въвличане & ниско & високо & високо \\
\hline Удовлетвореност & променлива & неизвестно & висока \\
\hline Взаимодействие с доставчика & ниско & неизвестно & високо \\
\hline на продукти/услуги & & & \\
\hline
\end{tabular}

Гремлър и Браун (Gremler \& Brown, 1996) извеждат множество причини според които твърденията за лоялността на пазара на потребителски стоки не са релевантни за лоялността в сектора на финансовите услуги. Последното бива извеждано като основен аргумент в тяхната разработка относно необходимостта от провеждане на повече изследвания по проблематиката. В академичните разработки на Гремльр и Браун (Gremler \& Brown, 1996, 1999) се търси отговор на два фундаментални въпроса: Какво е лоялността към доставчика на финансови услуги? и Кои са детерминантите които оказват влияние върху лоялността в 
сектора на финансовите услуги?. Те твърдят, че научните публикации в теорията за лоялността, основно са насочени към изучаване на потребителската лоялност към бранда, докато изследванията, посветени на клиентската лоялност в сектора на услугите са ограничени. Според Гремлър и Браун, клиентската лоялност е сложно, многоаспектно явление, което обхваща три отделни дименсии - поведенческа, отношенческа и когнитивна форма на лоялност. Извън традиционно изучаваните аспекти на лоялността поведенчески и свързани с нагласите, те добавят трета форма на проявление на лоялността „когнитивна“, в конструкта на явлението. Според авторите, когнитивната форма на лоялност поражда изникването на конкретен бранд на първо място в съзнанието на индивидите в процеса на вземане на решение за покупка. Тя може да бъде дефинирана като първия избор на клиента сред алтернативни пазарни предложения. В резултат на тяхната дискусия, Гремльр и Браун засягат тези три отделни дименсии и извеждат концептуална дефиниция за лоялността към услугите, според която лоялността е „степента, до която субектите изразяват позитивни нагласи, предразположение към доставчик на услуги, поведение на повторна покупка, както и възнамеряват да използват услугите единствено на този доставчик, когато възникне потребност от конкретен вид услуга“ (Gremler \& Brown, 1996, p. 176).

Сходен възглед за клиентската лоялност в сферата на финансовите услуги е този на Енев и Уайт. Те дефинират лоялния клиент като „индивид, който генерира стойност за бизнес организацията, вследствие на покупка на два или повече продукта от един доставчик" (Ennew \& Waite, 2007, p.298). Следователно, когато клиентьт изпита необходимост от информация или решение на съответен финансов проблем той сам поема инициативата, обръща се към конкретния доставчик с идеята да му предложи задоволително решение на възникналия проблем. Според авторите, лоялните клиенти достигат такова ниво на удовлетворение, доверие, ангажираност и прочие психологически предразположения към финансовия доставчик, предразполагащо към проява на активно поведение (т.е. последващи и свързани покупки) и задълбочаване на взаимоотношенията, въпреки потенциала за избор на алтернативни доставчици на финансови услуги. Засягат се трите отделни дименсии на лоялността в сектора на услугите, коментирани малко по-рано в разработката на Гремльр и Браун. Съответно поведенческа - два или повече продукта от един доставчик, отношенческа - ангажираност и доверие, и когнитивна - обръща се към текущия доставчик, въпреки потенциалната възможност за избор на алтернативни доставчици. От гледна точка на доверието, като предикор и необходимо условие за проява на лоялност, то намира изражение в обстоятелството, че банките и други финансови институции боравят със средствата на клиентите си. Всяка институция предлагаща финансови услуги е длъжна да носи отговорност при управлението на парите на клиентите и да гарантира тяхното финансово благополучие. Според Мейдън „отговорността на всяка организащия за финансови услуги е да пази интересите на своите клиенти“" (Meidan, 1996, p.4). При покупка на банков продукт по-същество клиента купува набор от обещания. Тъй като банковите продукти са нематериални и хетерогенни до момента на реалното изпълнение на услугата, клиентът няма гаранции дали съответната финансова организация ще изпълни предварително изявените обещания. Предвид последното, възприятията за корпоративния имидж и доверието във финансовия доставчик са ключов момент при привличане и задържане на клиентите. „Изграждането на доверие може да бъде фактор, който допринася за развиването на инерция във взаимоотношенията между финансовата институция и нейния клиент, тъй като подбора на доставчик носи със себе си много рискове и усилия за потребителя със съвсем малко гаранции“ (Харисън, 2004 р. 76), коментира Тина Харисън. В специализираната литература, често лоялността в сектора на услугите, бива свързвана с проявление на инертно поведение при покупка и ниска честота на 
смяна на една финансова институция с друга. Т.е. веднъж привлечен, клиента бива много лесно запазен и превръщането му в поведенчески лоялен. Така например, много от клиентите на банките по текущата сметка се считат, че попадат в тази категория. Те не разполагат с положително мнение за услугата която получават, но не сменят тяхната банкова сметка, защото процесът е твърде сложен или възприемат малко разлики между конкуриращите се банки (Ennew and Waite, 2007, p. 328). От друга страна, обещанията на банковите институции пораждат очаквания от страна на клиента. Потвърждаването на тези очакванията от фактическото изпълнение на услугата води до изграждане на доберие, високи висока степен на удовлетвореност и лоялност към доставчика на банкови услуги.

Бльомер и колектив (Bloemer, Ruyter, \& Peeters, 1998), изследвайки причините за проява на клиентската лоялност, адаптират концептуалната дефиниция на Джейкъби и Честнът (Jacoby \& Chestnut, 1978) в контекста на банковия сектор. Те определят лоялността към банката като „предубеден (т.е. неслучаен) поведенчески отговор (т.е. повторно посещение), изразен с течение на времето от някаква единици вземаща решение по отношение на една банка, сред набор от банки, която е функиия на психологически (вземане на решение и оценка) прочеси, водещи до ангажиране с марката" (Bloemer et al., 1998, p.277). Основният акцент в тяхната дефиниция е банковият ангажимент. Те определят банковия ангажимент като обвързаността на клиента с избора на банка или залогът, който субектьт е направил. Авторите поставят ангажираността като централно ядро, основа за развиване на лоялността към банката. При липсата на ангажираност с банковата институция, клиентът бива разглеждан като фалшиво лоялен. Според Бльомер, Руйтър и Питърс, ако процесът на вземане на решение а покупка и оценка на алтернативите не биват ограничени от външни или вътрешно психологически фактори, по дефиниция клиентът се ангажира при избора на банка. Въз основа на липсата, респ. наличието на ангажираност при избора е възможно да се установи степента на лоялност към конкретна банка. Тъй като нивото на ангажираност към всеки конкретен обект, случай, ситуация, избор и пр. е различно, авторите предполагат наличие на непрекъсната лоялност на пазара на банкови услуги. Следователно в единия край на континуума се намират истински лоялните клиенти - съчетание на висока степен на ангажираност с повтарящо се поведение при покупка, а в противоположна посока фалшиво лоялните - продължително посещение на банката, което не е основано на каквато и да било ангажираност с финансовата институция.

Рон Гарланд и Филип Гендъл (Garland \& Gendall, 2004) тестват валидността на концепцията за лоялността към бранда на Дик и Басу (Dick \& Basu, 1994), пренесена в контекста на пазара на банкови продукти. Основната цел залегнала в академичната разработка на Альн Дик и Кунал Басу (Dick \& Basu, 1994) е представяне на нова интегрирана концептуална рамка, хвърляща по-голяма яснота върху факторите, водещи до лоялно клиентско поведение. Те дефинират лоялността към бранда в зависимост от силата и посоката на връзка между относителните нагласи и делът на повторни покупки. Според тях лоялността е резултат както от благоприятно отношение към бранда, обект на оценка, изразявано в по-висока степен в сравнение към останалите пазарните алтернативи, така и последователно закупуване на една и съща марката (Dick \& Basu, 1994, p.100). Авторите издигат позитивните отношения към марката, като основа за изграждане на дългосрочните взаимодействия между пазарните участници - предложител и потребител. Тествайки тяхната концепция на пазара на банкови продукти, Гарланд и Гендал (Garland \& Gendall, 2004), твърдят, че модела им е особено валиден при абонаментни пазари, какъвто е банковият, където процента на оттичане на клиенти при конкурентни предложители е ниськ, а портфейла от услуги е малък. Те откриват, че истински лоялните клиенти ползват услугите на малък набор от банки, имат най-голяма вероятност да увеличат броя на използваните услуги от тяхната основна банка и ниска вероятност за смяна на доставчика на финансови 
услуги. Въз основа на регресионен анализ, авторите констатират, че както поведението, така и нагласите са фундаментални предиктори на лоялността към конкретна банка, както и броя на финансовите доставчици с които клиента е обвързан. Резултатите от тяхното изследване подкрепят типологията на Дик и Басу (Dick \& Basu, 1994) и привеждат емпирични доказателства за наличие на четири вида лоялност на пазара на банкови услуги, опровергавайки подобни предходни негативни резултати в различни сектори на икономиката. Гарланд и Гендъл достигат до заключението, че голям процент от клиентите превключват банки и обикновено имат портфейл от финансови институции, които използват, за задоволяване на техните специфични финансови потребности (Garland \& Gendall, 2004).

Според Фрагата и Мустакас във финансовия сектор конструкта на лоялността трябва да включва комбинация от „поведенчески, отнотенчески и когнитивни компоненти дългосрочни умишлени повторни покупки, висока степен на предпочитание, препоръка, застъпничество и ценова нечувствителност " (Fragata \& Moustakas, 2013, p.204). Авторите установяват, че зависимостта на броя използвани финансови доставчици е право пропорционална на размера на корпоративния клиент, т.е. големите фирми разпределят портфейла си с услуги в повече от една банка (средно 4,5), но концентрирайки финансовите си дела в една основа. Подобна тенденция се наблюдава и при банкирането на дребно. В годишния доклад на Bain \& Company (Toit \& Burns, 2016) „Лоялност на клиентите при банкиране на дребно: глобално издание 2016" се коментират последиците от полигамно лоялно поведение. Докладва се тенденцията клиентите да купуват високо приходни финансови услуги от конкурентни доставчици, докато основната им банка се задоволява с депозитни сделки, негенериращи нарастване на акционерното богатство. Според годишното издание през 2016 „кредитните карти, заемите, застраховките и инвестиционните продукти са най-закупуваните категории банкови услуги от конкурентите, докато основната банка има тенденщия да получава по-голям дял от нови депозитни сметки с ниска стойност "(Toit \& Burns, 2016).

Малко по-рано, Арън Джейн, Кристиан Пинсън и Нареш Малхотра (Jain et al., 1987) коментират полезността на лоялността като хипотетична конструкция при изучаване на банковия сектор. Авторите изучават лоялността на пазара на банкови продукти, извеждайки социално-икономическите, поведенческите и свързани с нагласите характеристики, като дискриминиращи променливи на лоялните, спрямо нелоялните домакинства. Джейн и колектив достигат до няколко основни заключения.

$\checkmark$ Информационната обезпеченост за финансовите услуги при лоялните клиенти е значително по-ниска в сравнение с познанията на нелоялните клиенти.

$\checkmark$ Ограничеността и липсата на опит в управлението на парите, водят до задълбочаване на взаимоотношения между банката и клиента.

$\checkmark$ Домакинствата третират лоялността си като стратегия за намаляване на риска при управление на финансови си дела.

$\checkmark$ Банково лоялните клиенти използват значително по-малко финансови услуги, т.е. разширеното портфолио от ползвани банкови продукти, повишава вероятността да изразят полигамно лоялно поведение.

$\checkmark$ Лоялните клиенти са заинтересовани от величината на потенциалния риск при покупка на банкови продукти и изразяват неблагоприятно отношение към заемане на средства.

Стъпвайки върху направеното изложение, в настоящата разработка под лоялност в контекста на банковата индустрия, се разбира съзнателна поведенческа реакция, проявена по линия на последователни покупки, в т.ч. повторни и свързани, от конкретна банка, сред набор от алтернативни такива, от субект, в лицето му на потребител вземащ 
решение, под влияние на силата на нагласите и позитивното отношение към доставчика на финансови услуги.

\section{Заключение}

Основно, диференцирането на клиентската лоялност при банкиране на дребно от останалите икономически сектори, произтича както от специфичната пазарна рамка, така и под влиянието на особеностите на финансовите продукти и тяхното отражение върху конструкта на явлението. От една страна банковата индустрия е култиватор на моногамна или още наричана изключителна лоялност. Наблюдаваното явление се аргументира с високите възприемани разходи за оттичане на текущата база клиенти към конкурентите, така и вследствие на възприеманата ниската степен на диференциация между пазарните алтернативи. От друга страна специфичният за сектора финансов риск, обуславя вероятността за полигамно лоялно поведение. С цел да намалят потенциалните рискове от съсредоточаване на финансовите си дела в една конкретна банка, клиентите често използват комплект от финансови предложители (Jain et al., 1987). Подобно явление е често срещано при покупка на инвестиционни услуги и спестовни продукти. Изграждане на „правилния“ корпоративен имидж, позитивни нагласи и ангажираност към финансовата организация, в голяма степен преодоляват склонността на клиента към такова поведение. Имайки предвид, че финансовият сектор става все по-динамичен и конкурентен, банките следва да съсредоточат усилията си върху дългосрочното задържане на съществуващите клиенти. Нарастващата тенденция към повишена клиентска мобилност и мултибанкиране, принуждава банковите мениджъри да отчитат, както специфичните за банковия продукт особености, така и спецификата на самата финансовата индустрия, с оглед максимизиране на позитивите от задържане на клиенти и изграждане на клиентска лоялност.

\section{References}

1. Bloemer, J., Ruyter, K. De, \& Peeters, P. (1998). Investigating drivers of bank loyalty: the complex relationship between image, service quality and satisfaction. International Journal of Bank Marketing, 17(7), 276-286.

2. Caruana, A. (2002). Service loyalty. European Journal of Marketing, 36(7/8), 811-828.

3. Dick, a. S., \& Basu, K. (1994). Customer Loyalty: Toward an Integrated Conceptual Framework. Journal of the Academy of Marketing Science, 22(2), 99-113.

4. Ennew, C., \& Waite, N. (2007). Financial Services Marketing. An International Guide to Principles and Practice. ELSEVIER.

5. Farley, J. U. (1964). Why Does "Brand Loyalty" Vary over Products? Journal of Marketing Research, 1(4), 9-14.

6. Fragata, A., \& Moustakas, E. (2013). Investigating loyalty determinants in business banking in offline and online environments. Journal of Economics, Business and Management, 1(2), 204208.

7. Fry, J., Shaw, D., Haehling von Lanzenauer, C., \& Cecil, D. (1973). Customer Loyalty to Banks : A Longitudinal Study. The Journal of Business, 46(4), 517-525.

8. Garland, R., \& Gendall, P. (2004). Testing Dick and Basu 's Customer Loyalty Model. Australasian Marketing Journal, 12(3), 81-87.

9. Gremler, D. D., \& Brown, S. W. (1996). Service loyalty: Its Nature, Importance, and Implications. Advancing Service Quality: A Global Perspective, (January 1996), 171-180.

10. Gremler, D. D., \& Brown, S. W. (1999). The loyalty ripple effect. International Journal of Service Industry Management, 10(3), 271-293. https://doi.org/10.1108/09564239910276872

11. Guest, L. (1944). A study of brand loyalty. Journal of Applied Psychology, 28(1), 16-27.

12. Hallowell, R. (1996). The relationships of customer satisfaction, customer loyalty, and 
profitability: An empirical study. International Journal of Service Industry Management, 7(4), 27-42.

13. Jacoby, J., \& Chestnut, R. W. (1978). Brand Loyalty, Measurement and Management. New York: John Wiley \& Sons Inc.

14. Jain, A. K., Pinson, C., \& Malhotra, N. K. (1987). Customer Loyalty as a Construct in the Marketing of Banking Services. International Journal of Bank Marketing, 5(3), 49-72.

15. Meidan, A. (1996). Marketing Financial Services. Macmillan Education UK.

16. Olson, J. C., \& Jacoby, J. (1971). A construct validation study of brand loyalty. Proceedings of the Annual Convention of the ..., (October). Retrieved from http://psycnet.apa.org/psycinfo/1971-25924-001

17. Rundle-Thiele, S., \& Bennet, R. (2001). A brand for all seasons? A discussion of brand loyalty approaches and their applicability for different markets. Journal of Product \& Brand Management, 10(1), 25-37.

18. Rust, R. T., Zaborik, A. J., \& Zahorik, A. J. (1993). Customer satisfaction, customer retention, and market share. Journal of Retailing, 69(2), 193-215.

19. Toit, G. du, \& Burns, M. (2016). Customer Loyalty in Retail Banking: Global Edition 2016. Retrieved October 3, 2018, from Bain\&Company website: https://www.bain.com/insights/customer-loyalty-in-retail-banking-2016

20. Wugayan, A., \& Pleshko, L. (2010). A STUDY OF SATISFACTION, LOYALTY, AND MARKET SHARE IN KUWAIT BANKS. Proceedings of the Academy for Studies in International Business, 10(1), 2-7.

21. Младенова, Г. (2015). Глобални тенденции в банкирането на дребно и маркетинговата им проекция в бъдещето. Икономически и Социални Алтернативи, 2, 35-51.

22. Харисьн, Т. (2004). Маркетинг на финансовите услуги. София: “Класика и стил ЕООД.” 